\title{
Yüksek Performanslı Çalışma Sistemleri ile Birey-Örgüt Uyumu Arasındaki İlişkide Duygusal Bağlılığın Aracılık Rolü
}

\author{
DOI: $10.26466 /$ opus.583814 \\ * \\ Tahir Akgemci* - Ertuğrul Tekin ${ }^{* *}$ - Serap Kalfaoğlu*** \\ * Prof. Dr, Selçuk Üniversitesi, İ̈BF, İşletme Bölümü, Konya / Türkiye \\ E-Posta: takgemci@selcuk.edu.tr \\ ORCID: 0000-0001-5936-7462 \\ ** Doktora Öğrencisi, Selçuk Üniversitesi, SBE, Yönetim ve Organizasyon ABD, Konya/ Türkiye \\ E-Posta: ertugrultekin42@gmail.com \\ ORCID: $0000-0001-8485-7316$ \\ *** Arş. Gör., Selçuk Üniversitesi, İ̈BF, İşletme Bölümü, Konya/ Türkiye \\ E-Posta: serapkalfaoglu@selcuk.edu.tr \\ ORCID: $\underline{0000-0002-7248-8370}$
}

Öz

Etkili ve verimli bir insan kaynakları yönetimi uygulamaları, işletme varlığının genişletilerek sürdürülebilmesinde ve pazar payının artırılmasında önemli bir yere sahiptir. İşletmelerin yüksek performanslı çalışma sistemleri kurabilmeleri için ise çalışanların örgüte ve diğger iş arkadaşlar ile duygusal bağlllık ilişkilerinin gelişerek birey-örgüt uyumunun başarılı bir şekilde sağlanması gerekir. Bu çalışmanın amacı yüksek performanslı çalışma sistemlerinin birey-örgüt uyumu üzerindeki etkisini analiz etmek ve bu ilişkide duygusal bağhllığın aracllı etkisinin olup olmadığını tespit etmektir. Bunun için oluşturulan hipotezler ve araştırma sorularl, Konya Organize Sanayi Bölgesinde faaliyet gösteren 7 sanayi işletmesindeki toplam 287 çalışana anket uygulanarak elde edilen verilerle test edilmiştir. Anket formunda yer alan ölçekler; Yılmaz ve Karahan (2005)'ın geliştirdiği 20 ifadeden oluşan "Yüksek Performanslı İnsan Kaynakları Yönetimi Uygulamaları Ölçeği", Türkçe'ye Elçi vd. (2008)'nin uyarladığı Netemeye vd. (1997)'nin geliştirdiği 4 ifadeden oluşan "Birey-Örgüt Uyumu Ölçeği" ve son olarak, Allen ve Mayer (1990) ile Wasti (2000) tarafından yapılan çalışmalarda kullanılmış olan ve 6 ifadeden oluşan "Duygusal Bağlılık Ölçeğg"dir. Analiz sonuçlar örgütlerde yüksek performansh çalışma sistemleri ile birey-örgüt uyumu ilişkisinde duygusal bağgllığın kısmi aracılık etkisinin olduğunu göstermektedir.

Anahtar Kelimeler: Yüksek Performansh Çalışma Sistemleri, Birey-Örgüt Uyumu, Duygusal Bağlllık 


\title{
The Mediating Role of The Emotional Commitment on The Effect of High Performance Working Systems on Person-Organization Fit
}

\begin{abstract}
Effective and efficient human resources management practices have an important role in expanding and maintaining the business presence and increasing the market share. In order for enterprises to establish high performance working systems, the relationship between employees and organization and other colleagues should be improved and person-organization fit should be ensured successfully. The aim of this study is to analyze the effect of high performance working systems on person-organization fit and to determine whether there is mediation effect of emotional commitment in this relationship. The hypotheses and research questions created for this purpose were tested with the data obtained by applying a questionnaire to the 287 employees in 7 industrial enterprises operating in Konya Organized Industrial Zone. The scales in the questionnaire form are as follows; "High Performance Human Resources Management Practices Scale" which consists of 20 statements developed by Yilmaz and Karahan (2005), Person-Organization Fit Scale" consisting of 4 statements which was adopted by Elçi et al. (2008) and developed by Netemeye et al. (199) and, finally, "Emotional Commitment Scale" used by the studies of Allen and Mayer (1990) and Wasti (2000) and consists of 6 statements. The results of the analysis show that there is a partial mediating effect of emotional commitment in high-performance working systems and person-organization fit relationship in organizations.
\end{abstract}

Keywords: High Performance Working Systems, Person-Organization Fit, Emotional Commitment 


\section{Giriş}

İnsan kaynakları yönetimi çalışmalarında; yüksek performanslı insan kaynakları uygulamaları (Sun ve Aryee, 2007, Yılmaz ve Karahan, 2014, Kalfaoğlu ve Erbaşı, 2018), yüksek performanslı iş-çalışma sistemleri (Elmas Atay vd., 2017) gibi çeşitli terimlerle adlandırılan Yüksek Performanslı Çalışma Sistemleri; çalışanların temel bir rekabet avantajı kaynağ olduğu düşünüldüğünde, bilgiye dayalı ekonomilerde ve hızla değişen çevrelerde giderek daha fazla önem kazanmaktadır (Prieto ve Santana, 2012, s.209). Bu sistemler aynı zamanda personelin bilgi ve becerilerini geliştirerek onların iş, çalışanlar ve işletmeye olan tutumlarını ve davranışlarını şekillendirerek örgütsel hedeflere ulaşmaya yardımcıdır (Chen, 2009).

Yüksek performanslı çalı̧̧ma sistemleri geleneksel hiyerarşik yönetim modelinin dışında personelin geniş kapsamlı eğitim almasıyla birlikte onların bireysel ve örgütsel gelişimi sonucunda üretkenliklerini arttırarak ve işletmenin sürdürülebilirliğini kolaylaştırarak uzun vadeli yaşamasını sağlar (Pak ve Kim, 2016). Yüksek performanslı çalışma sistemleri hem bireysel hem de örgütsel düzeyde çalışmalarla birlikte yenilikçi ve rekabetçi bir örgüt iklimi öngörür.

Bir işletmede çalışanlar çeşitli hedeflerini gerçekleştirmek üzere örgütsel yapıya dahil olmakla birlikte onların bireysel amaçları kimi zaman örgütün amaçlarıyla uyuşmayabilmektedir. Bu bağlamda bireyin amaçlarıyla örgütün amaçları arasındaki uyumu sağlayacak bir araç kullanarak mümkün olduğu kadar birey ile örgüt uyumu korunmaya çalışılmalıdır (Baysal, 1985, s.63). Bu amaçla bireyin davranışı örgütün değer ve normlarına göre düzenlenmelidir. Bireyin davranışının bireyin örgütü kendisi için çekici bulma noktasına göre şekilleneceği unutulmamalıdır. Bireyler uyum içinde olacakları örgütü tercih ettikleri takdirde örgüte olan bağlılıkları artarak aidiyet ve mensubiyet duygusu da gelişecektir. İşletmede bir birey olarak çalışanların örgütsel aidiyet ve mensubiyet duygusunun artmasıyla birlikte onların yaptıkları işle ilgili memnuniyet düzeyleri yükselerek bireysel performansları da artacaktır. Başarılı işletmelerde örgütün değerleri ile bireyin değerleri arasındaki uyum, birey olarak çalışanı örgüte daha da yaklaştırarak moral ve moti- 
vasyonunu yükseltir. Bu bağlamda yüksek performanslı çalışma sistemleri için gerekli birey örgüt uyumunu çalışana kazandırmada bireyin bağlı olduğu yöneticinin çok önemli bir rolü vardır (Besen, 2017, s.1).

Alan yazın incelendiğinde yüksek performanslı çalışma sistemleri, birey örgüt uyumu ve duygusal bağlılık ilişkisini aynı paydada ortaya koyan kapsamlı bir araştırmaya rastlanılmamıştır. Ancak bu kavramlar tekil veya ikili değişkenler halinde ele alındığında her birinin ortak bir etkileşim alanı oluşturduğu anlaşılmaktadır. Buna göre; yüksek performanslı çalışma sistemi ve duygusal bağlllık incelendiğinde birey-örgüt uyumu ve duygusal bağlllık arasındaki ilişkiyi Ogilvie (1986, s.335); insan kaynakları yönetimi uygulamalarının, çalışanların örgüte olan bağlılı̆̆ının kanıtı olarak görülürse, çalışanların duygusal bağlılıklarına olumlu biçimde katkıda bulunabileceğini ileri sürmektedir. Meyer vd. (2002, s.40)'ne göre yüksek performanslı insan kaynakları uygulamalarında çalışanların duygusal bağlılıklarının çalışma sürelerinden etkilendiğini ifade etmişlerdir. Trouba (2007, s.3)' ya göre, birey-örgüt uyumu üzerine yapılan araştırmalar örgüt kültürüne uygun işgören tercih edilmesinde faydalı olduğunu vurgulamaktadır. Güçlü bir birey örgüt uyumu ancak; bireyin kişiliğinin ve örgüte olan duygusal bağl1lı̆̆ının örgüt kültürü ve değerleri ile uyumlu olduğu zaman ortaya çıkmaktadır. Günümüzde rekabetçi sürdürebilirliğini sağlayabilmek için her yolu deneyimleyen örgütlerin yüksek performanslı çalışma sistemleri, birey-örgüt uyumu ve duygusal bağl1lık kavramlarının arz ettikleri önemi görmezden gelmeleri mümkün değildir. Buna rağmen literatürde bu üçlü ilişki sarmalını birlikte ele alan bir çalışmanın olmamasının, örgütler, yönetim ve çalışanlar gibi taraflar açısından önemli bir sorun teşkil ettiği düşünülmektedir. Bu araştırma da söz konusu ilişki ağını bir arada ele alması açısından önemlidir.

\section{Kavramsal Çerçeve}

Performans, bir işi yapan bireyin, bir grubun ya da bir örgütün o işle gerçekleştirilmek istenen hedefe yönelik olarak neye ulaşabildiğinin ve neyi sağlayabildiğinin nitel ya da nicel bir ifadesidir (Karakaş ve Ak, 2003, s.338). Yüksek performanslı çalışma sistemleri ise performansın yüksek olduğu sistemlerdir. Performans artışılla birlikte örgütsel başarı da 
yükselir. Örgütlerde, insan sermayesinin kurumun stratejik başarısı için en önemli faktörlerden biri olduğu anlayışıyla birlikte stratejik insan kaynakları yönetimine olan ilgi artmıştır. Stratejik insan kaynakları yönetimi örgütü bir bütün olarak çevresi ile uyumlu tutmak, ona rekabet üstünlüğü sağlamak ve stratejik amaçlarına ulaştırmak için birbirine bağlı olarak yürütülen çabaları ve kesintisiz biçimde sürdürülen bir yönetim anlayışını içerir. Yüksek performanslı çalışma sistemleri çalışanların bireysel performansların artışıyla birlikte örgütsel performans artışı da sağlayan stratejik insan kaynakları yönetimi araçlarından birisidir (Çalışkan, 2018, s.3). Yüksek performanslı çalışma sistemleri üstün yetenekleri olan ve bu yetenekleri işinde kullanmayı başaran, işle ilgili faaliyetleri daha yüksek işletme performansına ve sürdürülebilir rekabet avantajına dönüştürebilen, iş görenlerin seçilmesini, geliştirilmesini, işletmede tutulmasını ve motive edilmesini sağlayan birbiriyle bağlantılı insan kaynakları yönetimi uygulamalarının tümüdür (Way, 2002, s.765-766). Yüksek Performanslı Çalışma Sistemlerinin hem verimlilik ve kârlılık hem de çalışanların morali, motivasyonu, iş tatmini, iyi olma hali, örgüte bağlılığı, düşük işten ayrılma niyeti ve kurumsal sosyal performans gibi bir dizi performansla ilgili çıtılar üzerinde etkili olduğu ortaya konulmuştur. Yüksek performanslı çalışma sistemleri işletmelerde uygulamaya konulurken çalışanların bu yeni çalışma sistemine ilişkin algıları ve benimseme konusundaki isteklilikleri yüksek performanslı çalışma sisteminin başarısını etkiler (Garg ve Punia, 2017).

Kavramsal olarak incelendiğinde yüksek performanslı çalışma sistemleri; çalışanın bilgi birikimini, yeteneğini, katılımcılığını ve motivasyonunu maksimize etmeye yarayan süreç ve iş yapılarıyla ilgili belirli insan kaynakları uygulamaları olduğu görülür (Bohlander vd., 2001). Batt (2002) ise, yüksek performanslı çalışma sistemlerini üç ana boyuta ayırarak tanımlamıştır. Buna göre yüksek performanslı çalışma sistemleri; 1. Yüksek beceri ihtiyacı, 2. Çalışanların bilgi ve becerilerini diğer çalışanlarla birlikte kullanabilme, imkân ve serbestliğini veren iş tasarımı ve 3 . Bağlılık ve motivasyonu güçlendiren yapılar olarak ortaya çıar. İşletmelerde bağlığın sağladığı motivasyonla birlikte çalışanların bilgi ve becerilerini geliştirerek diğer çalışanlarla kullanarak yüksek performanslı çalışma sağladıkları sistemlerdir. Tanımlamalardan anlaşılacağı üzere, aslında 
yüksek performanslı çalışma sistemleri, insan kaynakları yönetim faaliyetlerinin, örgütsel boyutta uygulanması ile ortaya çıkmaktadır.

Örgüt yapısındaki herhangi bir işin, o işi yerine getiren veya getirecek herhangi bir bireyin kişilik yapısı, amaçları ve hedefi ile uyumlu olması önemlidir. Bu noktada, gerek bireysel ve gerekse örgütsel bağlamda; iş tatmini, iş verimi, etkinlik ve amaçların başarılması daha kolay gündeme gelebilecektir (Şimşek vd., 2014, s.94). Örgüt çalışanlarının motivasyonlu ve yüksek performansla çalışmasını sağlayabilmenin en önemli koşullarından birisi de, çalışanların örgütsel bağlılıklarının ve iş tatminlerinin artırılmasıdır (Özkan, 2018, s.88). Birey-örgüt uyumu, örgütün değerleri, hedefleri ve misyonu ile ortaya çıkan değerlere bireyin ne düzeyde uyum gösterdiğinin bir ölçüsüdür (Lauver ve Kristof-Brown, 2001, s.455). Kristof (1996) ise birey-örgüt uyumunu çalışanlar ve örgütler arasında ilişkilere göre değerlendirmiştir. Buna göre; birey-örgüt uyumu; bir tarafın diğer tarafın ihtiyaçlarını sağladığında, her iki tarafın da benzer temel özelliklere sahip olduklarında veya her ikisinin de var olduğu şartlarda ortaya çıkan uyum olarak tanımlanır (Kristof, 1996, s.4, Küçükodacı, 2014, s.5). Chatman (1989, s.333) ise birey-örgüt uyumunu; örgütün kültürel özellikleriyle kişilerin değerleri ve kişilik özelliğinin uyumu şeklinde tanımlamıştır. Literatürde birey-çevre uyumu genel alanı altında ele alınan birey-örgüt uyumu kısaca kişisel ve örgütsel değerlerin uyumudur (Eşitti ve Erdem, 2017, s.477). Doğru ürünün, doğru miktarda, doğru yerde, doğru zamanda ve doğru kalitede müşteriye ulaştırılmasında güçlü ve etkin bir işletme yapısı ve nitelikli işgücü imkanı ile mümkündür (Tekin ve Sayın, 2017, s.549)

Yapılan çalışmalarda birey-örgüt uyumunu sağlamanın dört farklı yolu olduğu ortaya konmaktadır. Bunlardan birincisi, kişinin işi için gerekli olan yetenek, kabiliyet, bilgi ya da iş gereklilikleri arasındaki uyumun sağlanmasıdır. İkincisi, örgütün genel yapısal sistemleri ve kişilerin ihtiyaçları arasındaki uyumun oluşumudur. Üçüncü, örgütün kültür ve değerleri ile kişinin kültür ve değerleri arasındaki uyumun sağlanmasıdır. Son olarak dördüncü ise, bireylerin kişiliği ve örgütün kişiliği diğer bir ifade ile örgütün iklimi arasındaki uyumun meydana gelmesidir (Judge ve Bretz, 1992, s.19; Polatçı ve Cindiloğlu, 2013, s.302).

Örgütsel Bağlllığın üç alt boyutundan (duygusal-devam-normatif) biri olan duygusal bağl1lık, Allen ve Meyer (1990, s.1-18) tarafından çalışanın 
örgütüne duygusal yakınlı duyup onunla özdeşleşmesi olarak tanımlanmıştır. Bu bağlamda duygusal bağlılığı güçlü olan çalışanlar örgütlerinin değerlerini, amaçlarını ve hedeflerini benimser; örgütün bir parçası olarak kalmak isterler. İşletmeye karşı duygusal bağlılık hissedenler, işlerinin gerektirdiği çabanın ötesinde çalışırlar ve duygusal bağlılık hissetmeyen çalışanlara göre daha fazla örgütte kalmak isterler (Alnıaçık vd., 2013, s.276). Duygusal bağllık, bir çalışanın bir şirketle birlikte, duygusal bir bağlılığa dayalı olma eğilimi olarak da tanımlanır.

Başka bir deyişle "duygusal bağlılık", organizasyonun hedefleri ve değerlerine yönelik bireylerin güçlü, pozitif tutumlarının bir bütünü olarak tanımlanabilir. Böyle bir olumlu tutum çalışanın organizasyonu ile özdeşlemesi, organizasyonel amaçları gerçekleştirmeye yönelik faaliyet göstermesi ve organizasyonla arasında duygusal bir bağ kurması neticesinde oluşur. Duygusal bağlllığa sahip bir çalışan kendisini örgütün bir parçası olarak gördügünden, örgüt onun için büyük bir anlam ve değer ifade eder (Tunalılar, 2018, s.106). Duygusal bağlılık kısaca işletmede çalışanların bir zorunluluk hissetmeden işine ve örgütüne bağlllık duyması kendini kuruma ait hissetmesi ve örgütte olmaktan mutlu olmasıdır. Duygusal bağlılık düzeyleri yüksek olan çalışanlar örgütü ve işlerini diğer çalışanlara göre daha fazla benimsemektedir.

\section{Metodoloji}

\section{Araştırmanın Amacı, Modeli ve Araştırma Soruları}

Araştırmanın temel amacı, çalışanların yüksek performanslı çalışma sistemlerine yönelik algısının birey-örgüt uyumu üzerindeki etkisini belirlemek ve bu ilişkide duygusal bağlılık algısının aracılık rolünün olup olmadığını tespit etmektir. Araştırmanın bağımsız değişkeni yüksek performanslı çalışma sistemleri, bağımlı değişkeni birey-örgüt uyumu ve aracı değişkeni de duygusal bağlılıktır. Baron ve Kenny (1986)'ya göre, bir değişkenin aracı değişken olabilmesi için gerekli ön şartlar (aktaran, Seçgin ve Özyer, 2016, s.266) 1) Bağımsız değişkenin aracı değişken üzerinde etkisi olmalıdır. 2) Bağımsız değişkenin bağımlı değişken üzerinde etkisi olmalıdır. 3) Aracı değişken analize dahil edildiğinde 
bağımlı değişken ile bağımsız değişken arasında daha önce yapılan analizde anlamlı olduğu görülen ilişkinin anlamlılık düzeyinin ya tamamen yok olması ya da önceki düzeye göre azalması gereklidir. Bu ilişkinin tamamen yok olması güçlü ve tek bir aracı değişken olduğuna, sıfır olmaması ise başka aracı değişkenlerinde olduğuna işaret etmektedir. Bu ön şartlar göz önünde bulundurularak hazırlanan araştırma modeli şekil 1'de yer almaktadır.

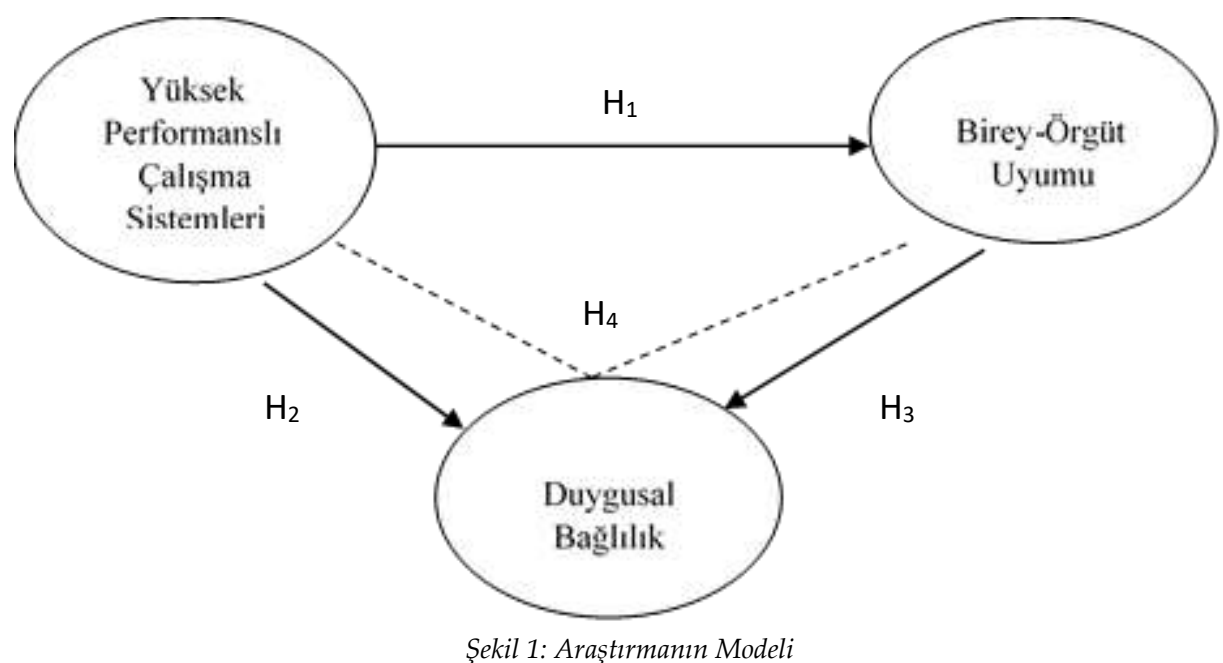

Oluşturulan araştırma modeli doğrultusunda ortaya konan araştırma soruları şu şekildedir:

1) yüksek performanslı çalışma sistemlerinin birey-örgüt uyumu üzerinde herhangi bir etkisi var mıdır?, 2) yüksek performanslı çalışma sistemlerinin duygusal bağlılık üzerinde herhangi bir etkisi var mıdır?, 3) duygusal bağlılı̆̆ın birey-örgüt uyumu üzerinde herhangi bir etkisi var mıdır? 4) yüksek performanslı çalışma sistemlerinin birey-örgüt uyumu üzerine etkisinde duygusal bağlılı̆̆ın aracılık etkisi var mıdır?

$\mathrm{Bu}$ doğrultuda araştırmanın hipotezleri aşağıdaki şekilde oluşturulmuştur;

- H1: Çalışanların yüksek performanslı çalışma sistemleri algısı birey-örgüt uyumunu etkiler. 
- H2: Çalışanların yüksek performanslı çalışma sistemleri algısı duygusal bağl1lık algisını etkiler.

- H3: Çalışanların duygusal bağlılık algısı birey-örgüt uyumunu etkiler.

- H4: Çalışanların yüksek performanslı çalışma sistemleri algısının birey-örgüt uyumuna etkisinde duygusal bağlılık algısının aracılık etkisi vardır.

\section{Araştırmanın Evreni ve Örneklemi}

Araştırmanın evrenini, Konya 3. Organize Sanayi Bölgesi'nde yer alan ve 7 adet otomotiv yedek parça üretimi faaliyetinde çalışan toplam 610 kişi oluşturmaktadır. Anketin doldurulma isteği gönüllülük esasına dayalı olup, dağıtılan anketler sırasında, bazı çalışanların izinli, bazılarının raporlu olması, bazılarının doldurmak istememesi, bazılarına ise iş başında doldurulmaya izin verilmemesi gibi zaman ve maliyet kıstaslarına ilişkin nedenler dolayısıyla tümüne sorular yöneltilememiştir. Toplanan anketlerin sayısı 287/610 adettir ve uygulanan anket 0,47 olmuştur. Bu sayı da yapılan istatistiki hesaplamalar neticesinde, $\% 95$ olasılık ve $\% 5^{\prime}$ lik bir hata payı ile evreni temsil edebilecek özelliktedir (Gürbüz ve Şahin, 2016, s.131).

\section{Araştırmada Kullanılan Veri Toplama Araçları}

Araştırmanın amacı doğrultusunda belirlenen hipotezleri test edebilmek için nicel bir araştırma yapılmıştır. Bu doğrultuda, anket formundan faydalanılmıştır. Anket formu, dört bölüm ve toplam 36 ifadeden oluşmaktadır. İlk bölümde yaş, cinsiyet, medeni durum, eğitim durumu, işletmede çalışma yılı, işletmede çalışma konumu bilgilerinin yer aldığ 6 soru bulunmaktadır. İkinci bölümde Yılmaz ve Karahan (2005) tarafından geliştirilen 20 ifadeden oluşan "Yüksek Performanslı İnsan Kaynakları Yönetimi Ölçeği" kullanılmıştır. Üçüncü bölümde Netemeye vd. (1997)'nin geliştirdiği 4 ifadeden oluşan "Birey-Örgüt Uyumu Ölçeği" kullanılmıştır. Ölçek, Türkçeye Elçi vd. (2008) tarafından uyarlanmıştır. Dördüncü bölümde Allen ve Mayer (1990) ile Wasti (2000) tarafından yapılan çalışmalarda kullanılmış olan ve 6 ifadeden oluşan "Duygusal 
Bağlılık Ölçeği" kullanılmıştır. Demografik bilgiler dışındaki bölümlerde yer alan ifadelerde 5'li Likert ölçeğinden faydalanılmış olup seçenekler (1) "kesinlikle katılmıyorum" dan; (5) "kesinlikle katılıyorum" a doğrudur. Araştırmanın istatistiksel analizleri SPSS 23.0 programiyla değerlendirilmiştir.

\section{Verilerin Analizi}

\section{Kullanılan Ölçeklere İlişkin Geçerlilik ve Güvenilirlik Analizleri}

Yüksek Performanslı İnsan Kaynakları Yönetimi ölçeğinin yapı geçerliliği test etmek için açıklayıcı faktör analizi uygulanmıştır. Kaiser Mayer Olkin (KMO) ile Barlett testleri değerleri ile öncelikle faktör analizine uygunluk test edilmiştir. KMO test sonucu değeri 0,954 ve Barlett testi önem sinaması değeri ise $\mathrm{p}=0,0001$ olarak tespit edilmiştir. Bu bilgiler ışığında faktörlerin ilişkilerinin değerlerince yüksek düzeyde açılandığı, örneklem sayısının yeterli olduğu ve veri setinin temel bileşenler analizine uygun olduğu kanıtlanmıştır. Yüksek Performanslı çalışma sistemleri ölçeği bu çalışmada tek boyutlu haliyle ölçülmüştür. Ölçeğe ait ifadelerin faktör yükleri 0,863 - 0,635 arasında değişmektedir.

Ayrıca Yüksek Performanslı İnsan Kaynakları Yönetimi ölçeği için Cronbach's Alpha değeri; 0,967 olarak belirlenmiştir. Yüksek Performanslı İnsan Kaynakları Yönetimi anketini oluşturan maddelerin homojen ve birbirleri ile ilişkili ifadeler olduğu bulunmuştur ( $F=18,588$, $\mathrm{p}=0,0001<0,05)$. Ayrıca testin toplanabilir özellikte olduğu tespit edilmiştir $(\mathrm{F}=1,139, \mathrm{p}=0,151>0,05)$. İnsan Kaynakları Yönetimi anketinin, Güvenilirlik Analizi uygulamaları bakımından, test tasarımının uygun yapıda olup olmadığını belirlemek için Hotelling's T-Squared Testi yapılmış ve test sonuçlarına göre modelin uygun yapıda olduğu bulunmuştur ( $F=7,488$, $\mathrm{p}=0,0001<0,05)$.

Birey Örgüt Uyumu Ölçeğinin yapı geçerliliği için yapılan analizler sonrasında KMO test sonucu değeri; 0,834 ve Barlett testi önem sınaması değeri ise $p=0,0001$ olarak saptanmıştır. Değerler doğrultusunda faktörlerin ilişkilerinin değerlerince yüksek düzeyde açılandığı, örneklem sayısının yeterli olduğu ve veri setinin temel bileşenler analizine uygun olduğu kanıtlanmıştır. Ölçek tek boyutlu olarak uygulanmış olup, 
ifadelerin faktör yükleri ise 0,957 - 0,935 arasında, oldukça yüksek düzeyde bulunmuştur.

Birey Örgüt Uyumu Ölçeği için Cronbach's Alpha değeri; 0,965 olarak saptanmıştır. Söz konusu ölçeğin maddelerinin homojen ve birbirleri ile ilişkili ifadeler olduğu, ilaveten testin toplanabilir özellikte olduğu tespit edilmiştir ( $F=6,776, p=0,0001<0,05 ; F=2,458, p=0,117>0,05)$. Birey Örgüt Uyumu ölçeğinin güvenilirlik analizi uygulamaları bakımından, test tasarımının uygun yapıda olduğu da belirlenmiştir (F=5,642, $\mathrm{p}=0,001<0,05)$.

Duygusal Bağlılık Ölçeğinin yapı geçerliliği için yapılan analizler sonrasında KMO test sonucu değeri; 0, 904 ve Barlett testi önem sınaması değeri ise $p=0,0001$ olarak saptanmıştır. Değerler doğrultusunda faktörlerin ilişkilerinin değerlerince yüksek düzeyde açıklandığı, örneklem sayısının yeterli olduğu ve veri setinin temel bileşenler analizine uygun olduğu kanıtlanmıştır. Ölçek tek boyutlu olarak uygulanmış olup, ifadelerin faktör yükleri ise 0,955 - 0,916 arasında, oldukça tatminkâr düzeyde bulunmuştur.

Duygusal Bağlllık Ölçeği için ise Cronbach's Alpha değeri; 0,865 olarak bulunmuştur. Duygusal Bağlılık maddelerinin homojen ve birbirleri ile ilişkili ifadeler olduğu, ayrıca testin toplanabilir özellikte olduğu tespit edilmiştir ( $\mathrm{F}=27,521, \mathrm{p}=0,0001<0,05 ; \mathrm{F}=0,860, \mathrm{p}=0,354>0,05)$. Duygusal Bağlılık Ölçeğinin Güvenilirlik Analizi uygulamaları bakımından, test tasarımının uygun yapıda olduğu da yine Hotelling's T-Squared Testi yardımıyla belirlenmiştir ( $\mathrm{F}=3,604, \mathrm{p}=0,004<0,05)$.

$\mathrm{Bu}$ değerlere 1şığında ölçekler literatürde kabul edilen güvenirlilik koşullarını yerine getirdiği ve bağımsız olarak iç tutarlılıklarının kabul edilebilir, iyi ölçüde olduğu görülmüştür.

\section{Demografik Özelliklere İlişkin Frekans Analizleri}

Araştırmaya katılan kişilerin \%87,8'i erkeklerden, \%12,2'si ise bayan katılımcılardan oluşmaktadır. Katılımcıların \%71,1'inin medeni hali evli iken, \% 28,9'unun bekârdır. Kişilerin \%36,6'sı 18-29 yaş arasında, \%38,7'sinin de 30-45 yaş arasında olduğu belirlenmiştir. Katılımcıların \%24,7'sinin ise 46 yaşından büyük olduğu saptanmıştır. Çalışmada bulunan kişilerin, 
\%17,4'ü ilkokul, \%23,0'ü ortaokul mezunu iken, \%26,8'i lise mezunu olduklarını belirtmişlerdir. Ayrıca kişilerin, \%6,6'sı ön lisans, \%23,0'ü lisans ve $\% 3,1$ 'i ise lisans üzeri eğitim programlarından mezun olduklarını bildirmişlerdir. Kişilerin \%10,8'i 1 yıldan daha az zamandır söz konusu şirkette çalıştıklarını ifade ederken, \%50,5'i 1-5 yıldır, \%25,1'i 6-10 yıldır ve $\% 13,6$ 'sı ise 11 yıl ve daha uzun zamandır aynı şirkette çalıştıklarını belirtmiştir. Araştırmada yer alan kişilerin \%0,3'ü işletmelerinde Genel Müdür/Müdür Yardımcısı, \%9,8'i Şef/Supervisor/Formen/Ustabaşı, \%10,1'i Bölüm veya Birim Müdürü / Müdür Yardımcısı olduğunu bildirirken, kişilerin \%79,8'i ise Çalışan olarak görev yapmakta olduklarını belirtmişlerdir (Tablo 1).

Tablo 1. Demografik Özelliklerle İlgili Bilgiler

\begin{tabular}{|c|c|c|c|}
\hline \multicolumn{2}{|c|}{ Demografik Özellikler } & \multirow{2}{*}{$\begin{array}{l}\text { Frekans } \\
252\end{array}$} & \multirow{2}{*}{$\begin{array}{l}\text { Oran }(\%) \\
87,8\end{array}$} \\
\hline Cinsiyetiniz & Erkek & & \\
\hline & Kadın & 35 & 12,2 \\
\hline \multirow{2}{*}{$\begin{array}{l}\text { Medeni } \\
\text { Durumunuz }\end{array}$} & Evli & 204 & 71,1 \\
\hline & Bekâr & 83 & 28,9 \\
\hline \multirow[t]{3}{*}{ Yaşınız } & $18-29$ & 105 & 36,6 \\
\hline & $30-45$ & 111 & 38,7 \\
\hline & 46 ve üzeri & 71 & 24,7 \\
\hline \multirow{6}{*}{$\begin{array}{l}\text { Eğitim } \\
\text { Durumunuz }\end{array}$} & İlkokul & 50 & 17,4 \\
\hline & Ortaokul & 66 & 23,0 \\
\hline & Lise & 77 & 26,8 \\
\hline & Ön Lisans & 19 & 6,6 \\
\hline & Lisans & 66 & 23,0 \\
\hline & Yüksek Lisans & 9 & 3,1 \\
\hline \multirow{4}{*}{$\begin{array}{l}\text { Bu işletmede } \\
\text { kaç yıldır } \\
\text { çalışmaktasınız? }\end{array}$} & 1 Yildan Az & 31 & 10,8 \\
\hline & $1-5$ Yil Arasi & 145 & 50,5 \\
\hline & $6-10$ Yil Arası & 72 & 25,1 \\
\hline & 11 Yil ve Daha Fazla & 39 & 13,6 \\
\hline \multirow{4}{*}{$\begin{array}{l}\text { İşletmedeki } \\
\text { Konumunuz } \\
\text { Nedir? }\end{array}$} & $\begin{array}{l}\text { Genel Müdür / Genel Müdür } \\
\text { Yrd. }\end{array}$ & 1 & 0,3 \\
\hline & $\begin{array}{l}\text { Şef/Supervisor/Formen/Usta- } \\
\text { baş1 }\end{array}$ & 28 & 9,8 \\
\hline & $\begin{array}{l}\text { Bölüm veya Birim Müdürü / } \\
\text { Müdür Yardımcısı }\end{array}$ & 29 & 10,1 \\
\hline & İş Gören / Çalışan & 229 & 79,8 \\
\hline
\end{tabular}




\section{Değişkenler Arasında Yapılan Korelasyon Analizi Bulguları}

Araştırmada çalışanların yüksek performanslı çalışma sistemleri algıları, birey-örgüt uyumu ve duygusal bağlılık arasındaki ilişkilerin varlığını ya da yokluğunu tespit etmek üzere korelasyon analizleri yapılmıştır. Yapılan bu analizlerle araştırma değişkenleri arasında pozitif veya negatif, anlamlı ya da anlamlı olmayan ilişkiler araştırılmıştır. Tablo 2' de bu ilişkiler özet olarak verilmiştir.

Tablo 2. Değişkenlere İlişkin Korelasyon Analizi Bulguları

\begin{tabular}{llllll}
\hline & Ort. & Std. Sapma & $\mathbf{1}$ & $\mathbf{2}$ & $\mathbf{3}$ \\
\hline $\begin{array}{l}\text { Yüksek Performanslı } \\
\text { Çalışma Sistemleri }\end{array}$ & 3,87 & 0,75 & 1 & & \\
\hline Birey-Örgüt Uyumu & 4,17 & 0,73 & $0,655^{* *}$ & 1 & \\
\hline Duygusal Bağlılık & 4,51 & 0,72 & $0,657^{* *}$ & $0,739^{* *}$ & 1 \\
\hline
\end{tabular}

${ }_{* *}^{* *}<0,01$ dïzeyinde anlamlidır.

Tablo 2' de yapılan korelasyon analizi sonucunda, tüm değişkenler (Yüksek Performanslı Çalışma Sistemleri, Birey-Örgüt Uyumu, Duygusal Bağlılık) arasında anlamlı ve pozitif yönlü ilişkiler olduğu görülmektedir.

\section{Değişkenler Arasında Yapılan Regresyon Analizi Sonuçları}

Bu kısımda hipotezleri test etmek amacıyla değişkenler arasında yapılan regresyon analizleri ve bu doğrultuda elde edilen bulgular tablo 3'de yer almaktadır.

Tablo 3'deki veriler incelendiğinde çalışanların yüksek performanslı çalışma sistemleri algısı birey-örgüt uyumunu pozitif yönde etkilemekte$\operatorname{dir}(\beta=, 571, \mathrm{p}=, 000)$, dolayısıyla $\mathrm{H}_{1}$ hipotezi kabul edilmiştir.

Çalışanların yüksek performanslı çalışma sistemleri algısı duygusal bağlılık algısını pozitif yönde etkilemektedir $(\beta=, 694, p=, 000)$, dolayısıyla $\mathrm{H}_{2}$ hipotezi kabul edilmiştir.

Çalışanların duygusal bağlılık algısı birey-örgüt uyumunu pozitif yönde etkilemektedir $(\beta=, 717, \mathrm{p}=, 000)$, dolayısıyla $\mathrm{H}_{3}$ hipotezi kabul edilmiştir. 
Tablo 3. Değişkenler Arasında Yapılan Regresyon Analizi Tablosu

\begin{tabular}{|c|c|c|c|c|c|c|c|c|}
\hline $\begin{array}{l}\text { Bağımlı } \\
\text { Değişken }\end{array}$ & $\begin{array}{l}\text { Bağımsız } \\
\text { Değişken }\end{array}$ & $\mathbf{R}^{2}$ & $\mathbf{F}$ & $\beta$ & $\mathbf{t}$ & $\mathbf{P}$ & $\begin{array}{l}\text { Durbin- } \\
\text { Watson } \\
(1,5-2,5)\end{array}$ & $\begin{array}{l}\text { Hipo- } \\
\text { tez }\end{array}$ \\
\hline $\begin{array}{l}\text { Birey- } \\
\text { Örgüt } \\
\text { Uyumu }\end{array}$ & $\begin{array}{l}\text { Yüksek } \\
\text { Performanslı } \\
\text { Çalışma } \\
\text { Sistemleri } \\
\end{array}$ & ,379 & 52,725 & ,571 & 13,624 & ,0001 & 1,678 & $\begin{array}{r}\mathrm{H}_{1} \\
\text { Kabul }\end{array}$ \\
\hline $\begin{array}{l}\text { Duygusal } \\
\text { Bağlilık }\end{array}$ & $\begin{array}{l}\text { Yüksek } \\
\text { Performanslı } \\
\text { Çalışma } \\
\text { Sistemleri } \\
\end{array}$ & ,431 & 34,224 & 694 & 14,703 & 0001 & 1,714 & $\begin{array}{r}\mathrm{H}_{2} \\
\text { Kabul }\end{array}$ \\
\hline $\begin{array}{l}\text { Birey- } \\
\text { Örgüt } \\
\text { Uyumu }\end{array}$ & $\begin{array}{l}\text { Duygusal } \\
\text { Bağlllık }\end{array}$ & ,546 & 59,989 & 717 & 18,5079 & 0001 & 1,655 & $\begin{array}{r}\mathrm{H}_{3} \\
\text { Kabul }\end{array}$ \\
\hline
\end{tabular}

\section{Yüksek Performansh Çalışma Sistemlerinin Birey-Örgüt Uyumu Üze- rine Etkisinde Duygusal Bă̆hlı̆̆ın Aracılık Rolünü İncelemeye Yöne- lik Yapılan Regresyon Analizi ve Bulgularn}

Baron ve Kenny (1986)'ya göre, bir değişkenin aracı değişken olabilmesi için gerekli ön şartlar göz ününde bulundurularak yapılan çoklu regresyon analizi ve bulguları tablo 4'de yer almaktadır.

Bir değişkenin aracılık rolüne sahip olup olmadığının belirlenmesi çoklu regresyon analizine bağlıdır ve bu analiz için ön şart değişkenler arası çoklu doğrusal bağlantının olmamasıdır. Söz konusu bağlantının varlığı VIF (Variance Inflation Factor (Varyans Genişlik Faktör Değeri)) ile anlaşılabilir ve bu değerin 10' dan az olması durumu çoklu bağlantının olmadığını destekler (Sevinç, 2013, s.2). Dolayısıyla modelimizdeki değişkenlerin VIF değerleri 1,715 çıktığından çoklu bağlantının olmadığı ve çoklu regresyon analizi yapılabildiği bulgusuna varılmıştır.

Tablo 4'deki, Baron ve Kenny'nin (1986) üçüncü koşulunun test edilmesi amacıyla yapılan regresyon analizi sonuçlarına göre; aracı değişken olan duygusal bağlılık algısı analize dahil edildiğinde, bağımlı değişken birey-örgüt uyumu ile bağımsız değişken yüksek performanslı çalışma sistemleri algısı arasında daha önce anlamlı olan $\beta=, 571$, aracı değişken olan duygusal bağlılik analize dahil edildikten sonra $\beta=, 283$ şeklinde azalmıştır, yani toplam etkinin ,288'lik kısmı duygusal bağlılık aracılığı ile 
ortaya çımaktadır. Bu durumda duygusal bağlılık algısının, yüksek performanslı çalışma sistemleri ile birey-örgüt uyumu arasında aracı değişken rolü üstlendiği söylenebilir. Bağımsız değişken etkisinin son analizde tamamen yok olmaması, bu ilişkide başka aracı değişkenlerin de olabileceğini ortaya koymaktadır (Baron ve Kenney, 1986, s.1173-1182'den aktaran Turunç ve Çelik, 2010, s.197). Bu da yüksek performanslı çalışma sistemleri algısının, birey-örgüt uyumu ile ilişkisinde duygusal bağlılık alg1sının “kısmi aracı değişken” olduğunu göstermektedir. Böylece araştırmanın son hipotezi olan $\mathrm{H}_{4}$ hipotezi de kabul edilmiştir.

Tablo 4. Yüksek Performanslı Çalışma Sistemlerinin Birey-Örgüt Uyumu Üzerine Etkisinde Duygusal Bă̆lılı̆̆ın Aracılık Rolünü İncelemeye Yönelik Yapılan Regresyon Analizi ve Bulguları

\begin{tabular}{|c|c|c|c|c|c|c|}
\hline \multicolumn{7}{|c|}{ 1-Bağımlı Değişken: Duygusal Bağlılık } \\
\hline Bağımsız Değişken & $\mathbf{R}^{2}$ & $\mathbf{F}$ & $\beta$ & $t$ & $\mathbf{P}$ & \\
\hline $\begin{array}{l}\text { Yüksek Performanslı } \\
\text { Çalışma Sistemleri }\end{array}$ & 431 & 34,224 & 694 & 14,703 & ,000 & \\
\hline \multicolumn{7}{|c|}{ 2-Bağımlı Değişken: Birey-Örgüt Uyumu } \\
\hline Bağımsız Değişken & $\mathbf{R}^{2}$ & $\mathbf{F}$ & $\beta$ & $t$ & $\mathbf{P}$ & \\
\hline $\begin{array}{l}\text { Yüksek Performanslı Ça- } \\
\text { lışma Sistemleri }\end{array}$ & 379 & 52,725 &, 571 & 13,624 & 000 & \\
\hline \multicolumn{7}{|c|}{ 3-Bağımlı Değişken: Birey-Örgüt Uyumu } \\
\hline Bağımsız Değişken & $\mathbf{R}^{2}$ & $\mathbf{F}$ & $\beta$ & $t$ & $\mathbf{P}$ & $\begin{array}{l}\text { VIF } \\
\text { (Variance } \\
\text { Inflation } \\
\text { Factor) }\end{array}$ \\
\hline $\begin{array}{l}\text { Yüksek Performanslı } \\
\text { Çalışma Sistemleri }\end{array}$ & ,519 & 65,324 & ,283 & 4,964 & ,000 & 1,715 \\
\hline Duygusal Bağlılık & & & ,402 & 6,086 & ,000 & 1,715 \\
\hline
\end{tabular}

${ }^{* *} p<0,01$ ve **$p<0,05$ düzeyinde anlamlıdır.

Son olarak test edilen hiyerarşik regresyon analizi ile beliren aracılık etkisinin anlamlı olup olmadığının Sobel testi ile doğrulandığ lebilir. Bu test sonucu elde edilen $Z$ skor puanı $(5,908)$ 1,96 değerinden büyük ve p değeri $(, 000)$ anlamlı olduğu için yapılan hiyerarşik regresyon analizi sonrası belirlenen aracılığın varlığı ve anlamlılığı kanıtlanmıştır. 


\section{Sonuç ve Öneriler}

Yüksek performanslı çalışma sistemleri işletmede bireysel çalışan katılımı, bağlılı̆̆1 ve yetkilendirilmesi sonucu başarıyı artırır. Yüksek performanslı çalışma; katı işe alım prosedürleri, geniş eğitim süreçleri, bilgi paylaşımı, iş tasarımı, tanıtım kanalları içinde, çalışan izni ve performansa dayalı ödeme dâhil olmak üzere ilgili insan kaynakları yönetimi uygulamalarından oluşan organik bir sistem olarak görülmektedir. Yüksek performanslı çalışma sisteminin uygulanmasıyla, çalışanın işe katılım olasılığı artarak yüksek kaliteli insan sermayesi korunur.

Türkiye'de yapılan sınırlı sayıda olan yüksek performanslı çalışma sistemleri ile ilgili araştırmalarda, örneğin, Elmas Atay vd. (2017) 'de yaptıkları çalışmada, yüksek performanslı çalışma sistemleri ile örgüte bağlılık arasında pozitif ve olumlu bir ilişkiler tespit edilmiştir. Yüksek performanslı çalışma sistemleri ile iş tatmini arasındaki ilişkiyi inceleyen Gürbüz (2009), İstanbul'daki şirketler üzerinde incelemeler yapmış ve yüksek performanslı çalışma sistemi uygulamalarının olduğu iş yerlerinde iş tatmininin daha yüksek olduğunu tespit etmiştir. Tekstil sektöründe çalışanların yüksek performanslı insan kaynakları yönetimi uygulamaları, psikolojik güçlendirme ve duygusal bağlılık arasındaki ilişkileri inceleyen Yılmaz ve Karahan (2014) ise yüksek performanslı insan kaynakları yönetimi uygulamalarının, psikolojik güçlendirme ve duygusal bağlılık üzerinde istatistiksel olarak anlamlı ve pozitif yönde bir etkiye sahip olduğunu tespit etmiştir. Uluslararası alanda yapılan çalışmalarda ise Kumari ve Afroz (2013) Hindistan Sonbhadra Bölgesindeki 200 yöneticiye yaptıkları çalışmada, örgütsel ve duygusal bağlılığın yönetim alanında çalışanlarla, iş yaşam memnuniyeti arasında olumlu ilişki olduğunu tespit etmişlerdir. Yine, Kehoe ve Wirght (2013) örgütte yüksek performanslı insan kaynakları uygulamalarının, duygusal bağlılık ve örgütsel bağlılıkla olumlu yönde ilişkili olduğunu tespit etmişlerdir.

Yüksek performanslı çalışma sistemleri ile ilgili literatürde yapılan sektörler incelendiğinde sanayi sektörü (Çalışkan, 2018; Yılmaz ve Karahan, 2014; Elmas Atay vd., 2017; Kehoe ve Wright, 2013), turizm sektörü (Limon, 2012), bankacılık sektörü (Özutku, 2018), özel sektör (Kalfaoğlu ve Erbaş1, 2018) gibi birçok sektör çalışmalara konu olmuştur. Aynı zamanda literatürün alan bazlı incelenmesi sonucunda, örgütsel vatandaşlık 
davranışı ve yabancılaşma arasındaki ilişki (Çalışkan 2018), iş erteleme davranışı ve iş stresi ilişkileri (Kalfaoğlu ve Erbaşı, 2018), işletme performansına etkisini (Limon, 2012), psikolojik güçlendirme ve duygusal bağlllık ilişkisini (Yılmaz ve Karahan, 2014), örgütsel bağlılık (Elmas Atay vd. 2017), tutum ve davranışlara etkisini (Kehoe ve Wright, 2013), oryantasyon ve örgütsel öğrenme gibi bir çok farklı alanda çalışmanın yapıldığı görülmüştür.

Birey-örgüt uyumu ile ilgili olarak ise eğitim sektörü (Özkan, 2018; Yücel ve Çetinkaya, 2016), gıda sektörü (Eşitti ve Erdem, 2017), otomotiv sektörü (Besen, 2017), kamu sektörü (Westerman ve Cyr, 2004), özel sektör (Swiatek-Barylska, 2017) gibi pek çok sektörde çalışmalar yapılmıştır. Aynı zamanda literatürün alan bazlı incelenmesi sonucunda, inovasyon üzerindeki etkileri (Eşitti ve Erdem, 2018), örgütsel bağlllık (Yücel ve Çetinkaya, 2016; Dündar, 2016) iş stresi ve verimlilik (Ulutaş, 2011) konuları incelenmiştir. Ayrıca; bireysel performans (Özkan, 2018), örgütsel davranış (Swiatek-Barlyska, 2017) gibi çok farklı alanlarda çalışmalar yapıldığı da görülmektedir.

Duygusal bağlılık konusu ile ilgili sektörler incelendiğinde ise, turizm sektörü (Çalışkan ve Dedeoğlu, 2017), üretim sektörü (Büyükyılmaz vd., 2018), gıda sektörü (Gürbüz, 2006), kamu sektörü (Akdemir ve Çalış Duman, 2016), özel sektör (Aghdasi vd., 2011) gibi çoğu sektör çalışmalara konu olmuştur. Alan bazlı literatür incelemesi sonucunda, iş tatminini (Büyükyılmaz vd., 2018), iş gören performansını (Akdemir ve Duman, 2016), iş stresi (Aghdasi vd., 2011) konularında farklı alanlarda çalışmalar yapıldığı görülmektedir.

Bu çalışma Konya Sanayi Bölgesinde; 7 otomotiv ve yedek parça üreten sanayi işletmesi ve 287 çalışan ile sınırlı tutularak uygulanmıştır. Araştırmacılar konuyu farklı bölgelerde ve sektörlerde daha çok işletme ve çalışan üzerinde yapabilirler. 
EXTENDED ABSTRACT

\title{
The Mediating Role of The Emotional Commitment on The Effect of High Performance Working Systems on Person-Organization Fit
}

\author{
Tahir Akgemci - Ertuğrul Tekin - Serap Kalfaoğlu \\ Selçuk University
}

When the literature is examined, there is not a comprehensive study that shows the relationship between high performance working systems, individual organizational harmony and emotional commitment on the same denominator. However, when these concepts are considered as single or binary variables, it is understood that each of them constitutes a common area of interaction. According to this; the relationship between individualorganizational adaptation and emotional commitment when the high-performance study system and emotional commitment were examined Ogilvie (1986, p.335) suggests that human resource management practices can positively contribute to employees' emotional commitment if they are seen as evidence of their commitment to the organization. Meyer et al. (2002, p.40) states that employees' emotional commitment is influenced by their working hours in high performance human resources applications. According to Trouba (2007, p.3), researches on individual-organizational harmony emphasize that it is beneficial in favor of employees according to organizational culture. A strong individual-organizational harmony occurs when the personality of the individual and his emotional commitment to the organization are compatible with the organizational culture and values. Today, it is not possible for organizations experiencing all ways to achieve competitive sustainability by ignoring the importance of the concepts of high performance working systems, individual-organizational harmony and emotional commitment. Nevertheless, it is thought that the absence of a study that considers this triple relationship spiral in 
the literature poses a significant problem for the parties such as organizations, management and employees. This research is important in terms of addressing this relationship network together.

The main aim of the study is to determine the effect of employees' perception of high performance working systems on individual-organization compliance and to determine whether there is an mediator role in this relationship. The independent variable of the study is high performance work systems, the dependent variable is individual-organizational harmony and the agent variable is emotional commitment.

In this direction, the hypotheses of the research are formed as follows;

- H1: Employees' perception of high-performance working systems affects individual-organizational compliance.

- H2: Employees' perception of high-performance working systems affects the perception of emotional commitment.

- H3: Employees' perception of emotional commitment affects individual-organizational compliance.

- H4: The perception of emotional commitment has an mediating effect of the the perception of employees' high performance working systems on the individual-organization harmony.

The population of the study consists of a total of 610 people working in 7 spare parts production in Konya 3. Organized Industrial Zone. The number of questionnaires collected was $287 / 610$ and the applied questionnaire was 0.47 .

As a result of the correlation analysis, it is seen that there is a significant and positive relationship between all variables (High Performance Work Systems, Individual-Organizational Harmony, Emotional Commitment).

As a result of the regression analysis, the high performance working systems perception of the employees positively affects the individual-organization compliance $(\beta=, 571, \mathrm{p}=, 000)$, therefore the $\mathrm{H} 1$ hypothesis is accepted.

Employees' perception of high performance working systems positively affects the perception of emotional engagement $(\beta=694, p=000)$ and hence the $\mathrm{H} 2$ hypothesis was accepted.

Emotional commitment of the employees positively affects the individual-organization compliance $(\beta=, 717, p=, 000)$, hence the hypothesis H3 was accepted. 
According to the results of regression analysis conducted by Baron and Kenny (1986) for testing mediation; when emotional commitment perception, which is a tool variable, was included in the analysis, $\beta=571$, which was meaningful between the dependent variable individual-organizational compliance and the perception of high-performance working systems, decreased by $\beta=283$ after being included in the analysis. In other words, 288 of the total effect arises through emotional commitment. In this case, it can be said that the perception of emotional commitment plays an intermediary variable between high performance working systems and individual-organizatioaln compliance. The fact that the independent variable effect does not disappear completely in the last analysis reveals that there may be other mediating variables in this relationship (Turunç and Çelik, 2010, p. 197 from Baron and Kenney, 1986, p.1173-1182). This situation shows that the perception of emotional commitment is in partial mediator variable in the relationship between high-performance working systems perception and individual-organizational harmony. H4 hypothesis, which was the last hypothesis of the study, was accepted.

Finally, it can be stated that Sobel test is confirmed whether the mediating effect which is revealed by the hierarchical regression analysis is significant. The $\mathrm{Z}$ score score (5.908) obtained as a result of this test was greater than 1.96 and $p$ value $(, 000)$ was significant.

This study was conducted in Konya Industrial Zone; limited 7 industrial and automotive spare parts and 287 employees. Researchers can do this on more businesses and employees in different regions and sectors.

\section{Kaynakça / References}

Aghdasi, S., Kiamanesh, A. R. ve Ebrahim, A. N. (2011). Emotional intelligence and organizational commitment: Testing the mediatory role of occupational stress and job satisfaction. Procedia-Social and Behavioral Sciences, 29, 1965-1976.

Akdemir, B. ve Çalış-Duman, M. (2016). Duygusal bağlllık ve işgören performansı arasındaki ilişkiye yönelik bir araştırma. The Journal of Academic Social Science Studies, 46, 343-357. 
Allen, N. J. ve Meyer, J. P. (1990). The measurement andantecedents of affective, continuance and normative commitment to the organization. Journal of Occupational Psychology, 63, 1-18.

Alnıaçık, E., Ü., Alnıaçık, S. ve Erat, K. A. (2013). Does person-organization fit moderate the effects of affective commitment and job satisfaction on turn over intentions?. Procedia Social and Behavioral Sciences, 99, $274-281$.

Baysal, A. C. (1985). Birey-örgüt bütünleşmesinde davranışsal yaklaşımlar. İstanbul Üniversitesi İşletme Fakültesi Dergisi, 14 (1), 63-83.

Batt, R. (2002). Managing customer services: Human resource practices, quitrates, and sales growth. Academy of Management Journal, 45, 587-597.

Besen, E. (2017). Birey-örgüt uyumu ve yöneticiye duyulan güven ile lider-üye etkileşimi bağlamında Bursa'da otomotiv sektörü çalı̧̧anları üzerinde bir araştırma. Yüksek Lisans Tezi, Bahçeşehir Üniversitesi Sosyal Bilimler Enstitüsü, İstanbul.

Bohlander, G., Snell, S. ve Sherman, A. (2001). Managing human resource. (12th Ed.), Cincinnati:South Western College.

Büyükyılmaz, O., Karakulle, İ. ve Karataş, İ. (2018). Örgütsel kariyer yönetiminin duygusal bağlılık üzerindeki etkisinde iş tatmininin aracllık rolü. Çankırı Karatekin Üniversitesi İktisadi ve İdari Bilimler Fakültesi Dergisi, 8 (1), 1-29.

Chatman, J. A. (1989). Improving interactional organizational research: A model of person-organization fit. The Academy of Management Review, 14 (3), 333-349.

Chen, C. J. (2009). Strategic human resource practices and innovation performance: The mediating role of knowledge management capacity. Strategic Direction, 62 (6), 104-114.

Çalışkan, Ç. (2018). Yüksek performanslı çalışma sistemleri algısı, örgütsel vatandaşlık davranışı ve yabancılaşma arasındaki ilişkiler. Yüksek Lisans Tezi, Osmangazi Üniversitesi Sosyal Bilimler Enstitüsü, Eskişehir.

Çalışkan, C. ve Dedeoğlu, B. B. (2017). Psikolojik iklim ve duygusal bağl1lık ilişkisinde duygu gösterim kurallarının aracılık rolü: Oteller üzerine bir araştırma. Seyahat ve Otel İşletmeciliği Dergisi, 14 (3), 121-134. 
Elçi, M., Alpkan L. ve Çekmecelioğlu, G. H. (2008). The influence of person organization fit on the employee's perception of organizational performance. 4th International Strategic Management Conference, Sarajevo, Bosnia-Herzegovnia, June, 19-21, 587-593.

Elmas Atay, S., Gerçek, M. ve Uyargil, C. (2017). Yüksek performanslı iş sistemlerinin örgüte bağlllık üzerindeki etkisine ilişkin bir araştırma. Süleyman Demirel Üniversitesi İibf Dergisi, 22 (2), 253-266.

Eşitti, B. ve Erdem, H. (2017). Birey-örgüt uyumunun örgütsel inovasyon üzerindeki etkileri: Yiyecek-içecek işletmeleri üzerine bir araştırma. Manas Sosyal Araştırmalar Dergisi, 6 (4), 475-489.

Garg, N. ve Punia, B.K. (2017). Developing high performance work system for Indian insurance industry. International Journal Of Productivity And Performance Management, 66 (3), 320 - 337.

Gürbüz, S. (2009). The effect of high performance hr practices on employees' job satisfaction. İstanbul Üniversitesi İşletme Fakültesi Dergisi, 38 (2), 110-123.

Gürbüz, S. ve Şahin, F. (2016). Sosyal bilimlerde araştırma yöntemleri, (3. Baskı). Ankara: Seçkin Yayıncılık.

Judge, T. A. ve Bretz, R. D. (1992). Effects of work values on job choice decisions. Journal of Applied Psychology, 77 (3), 1-35.

Karakaş, B. ve Ak, R. (2003). Kamu yönetiminde performans yönetimi önemli midir?, Kamu Yönetiminde Kalite 3. Ulusal Kongresi Bildirileri, 04-05 Aralık 2003, Ankara:Todaie Yayınları.

Kalfaoğlu, S. ve Erbaşı, A. (2018). Yüksek performanslı insan kaynakları yönetimi uygulamaları, iş erteleme davranışı ve iş stresi ilişkileri. Akademik Sosyal Araştırmalar Dergisi, 6 (84), 375-388.

Kehoe, R. R. ve Wright, M. P. (2013). The impact of high-performance human resource practices on employees, attitudes and behaviors. Journal of Management, 39 (2), 636-653.

Kristof, A. L. (1996). Person-organization fit: an integrative review of its conceptualizations, measurement, and implications. Personnel Psychology, 49 (1), 1-49.

Kumari, N. ve Afroz, N. (2013). The impact of affective commitment in employees life satisfaction. Global Journal of Management and Business Research Interdisciplinary, 13 (7), 24-30. 
Küçükodacı, B. Z. (2014). Birey-örgüt uyumu, örgütsel adalet algısı ve işten ayrılma niyeti arasındaki ilişki üzerine bir araştırma. Yüksek Lisans Tezi, Marmara Üniversitesi Sosyal Bilimler Enstitüsü, İstanbul.

Lauver, K. J. ve Kristof-Brown, A. (2001). Distinguishing between employees' perceptions of person-job and person-organization fit. Journal of Vocational Behavior, 59 (3), 454-470.

Limon, H. (2012). Yüksek başarımlı çalışma sistemlerinin işletme performansı üzerindeki etkisi: Konaklama işletmelerinde bir uygulama. Yüksek Lisans Tezi, Nevşehir Üniversitesi, Sosyal Bilimler Enstitüsü, Nevşehir.

Meyer, J. P., Stanley, D. J., Herscovitch, L. ve Topolnytsky, L. (2002). Affective, Continuance, and normative commitment to the organization: A meta-analysis of antecedents, correlates, and consequences. Journal of Vocational Behavior, 61, 20-52.

Ogilvie, J. R. (1986). The role of human resource management practices in predicting organizational commitment. Group \& Organization Management, 11 (4), 335-359.

Özkan, S. Ö. (2018). Psikolojik sermayenin bireysel performans üzerindeki etkisinde birey-örgüt uyumunun aracllı rolü. Doktora Tezi, Türk Hava Kurumu Üniversitesi Sosyal Bilimler Enstitüsü, Ankara.

Özutku, H. (2018). Yüksek performanslı çalışma uygulamaları ölçeğinin türkçe'ye uyarlaması, geçerlik ve güvenirlik analizi. Hacettepe Üniversitesi İktisadi ve İdari Bilimler Fakültesi Dergisi, 36 (3), 141-164.

Pak, J. ve Kım, S. (2016). Team managers implementation, high performance work systems intensity, and performance: A multilevel investigation. Journal of Management, 44 (7), 2690-2715, Do1: 0149206316646829.

Polatçı, S. ve Cindiloğlu, M. (2013). Kişi-örgüt uyumunun örgütsel vatandaşlık davranışına etkisi: Duygusal bağlılığın aracılık rolü. Süleyman Demirel Üniversitesi İktisadi ve İdari Bilimler Fakültesi Dergisi, 18 (3), 299-318.

Prieto, I. M. ve Santana, M. P. P. (2012). Building ambidexterity: The role of human resource practices in the performance of firms from spain. Human Resource Management, 51 (2), 189-211. 
Seçgin, Y. ve Özyer, K. (2016). Kontrol odağının örgütsel bağlllık üzerine etkisinde personel güçlen-dirmenin aracılık rolü: Ankara il merkezindeki dört ve beş yıldızlı otel işletmelerinde bir araştırma. International Journal of Eurasia Social Sciences, 7 (22), 249-277.

Sevinç, E. (2013). Çoklu regresyon korelasyon analizinde varsayımdan sapmalar ve çimento sektörü üzerine uygulama. Yüksek Lisans Tezi. İstanbul: İstanbul Üniversitesi, İşletme Fakültesi, Finans Anabilim Dalı. 18.02.2019 tarihinde Http://Serpam.Org/Wp-Content/Uploads/Sevinc2013.Pdf adresinden erişilmiştir.

Swratek-Barylska, I. (2017). Images of person-organization fit: Elements affecting employee organizational behavior. Kelaniya Journal of Management, 5 (2), 17-31.

Sun, L. Y. S. ve Aryee, K. S. (2007). High performance human resource practices, citizenship behavior, and organizational performance, a relational perspective. Academy of Management Journal, 50 (3), 558577.

Şimşek, Ş., Çelik, A. ve Akgemci, T. (2014). Davranış bilimlerine giriş ve örgütlerde davranış. (8. Baskı), Konya: Eğitim Kitabevi.

Tekin, M. ve Sayın, A. A. (2017). Lojistik faaliyetlerde satın alma faaliyetinde karşılaşılan riskler ve perakende sektöründe uygulaması. Kesit Akademi Dergisi, 3 (10), 545-569.

Trouba, E. J. (2007). A person-organization fit study of the big five personality model and attraction to the organizations with varying compensation system characteristics, Department Of Psycology College Of Liberal Arts And Sciences Depaul University Chicago İllinois, Umı Microform.

Tunalılar, T. T. (2018). Yöneticinin kültürel zekâsının çalışanların duygusal bağhlı̆̆ıyla ilişkisi ve ilişki uzaklığının düzenleyici rolü: Bir araştırma, Doktora Tezi, İnönü Üniversitesi Sosyal Bilimler Enstitüsü, Malatya.

Turunç, Ö. ve Çelik, M. (2010). Çalışanların algıladıkları örgütsel destek ve iş stresinin örgütsel özdeşleşme ve iş performansına etkisi, Yönetim ve Ekonomi, 17 (2), 183-206.

Way, S. A. (2002). High Performance Work Systems And İntermediate İndicators Of Firm Performance With İn The Us Small Business Sector. Journal of Management, 28, 765-785. 
Westerman, J. W. ve Cyr, L. A. (2004). An integrative analysis of personorganization fit theories, International Journal of Selection and Assessment, 12 (3), 252-261.

Yılmaz, H. ve Karahan, A. (2014). Yüksek performanslı insan kaynakları yönetimi uygulamaları, psikolojik güçlendirme ve duygusal bağlılık arasındaki ilişkilerin incelenmesi: Tekstil sektöründe bir araştırma, Dokuz Eylül Üniversitesi Sosyal Bilimler Enstitüsü Dergisi, 16 (4), 607-637.

Yücel, İ. ve Çetinkaya, B. (2016). Birey-örgüt uyumu ile örgütsel bağlılık arasındaki ilişkide cinsiyetin rolü: Kayseri örneği, Aksaray Üniversitesi İktisadi ve İdari Bilimler Fakültesi Dergisi, 8 (3), 17-30.

\section{Kaynakça Bilgisi / Citation Information}

Akgemci, T., Tekin, E. ve Kalfaoğlu, S. (2019). Yüksek performanslı çalışma sistemleri ile birey-örgüt uyumu arasındaki ilişkide duygusal bağlılığın aracılık rolü. OPUS-Uluslararası Toplum Araştırmaları Dergisi, 12(18. UİK Özel Sayı), 197-217. DOI: 10.26466/opus.535618. 